\title{
Limited Liability and Mechanism Design in Procurement*
}

\author{
Roberto Burguet, ${ }^{\dagger} J u a n-J o s e ́ ~ G a n u z a^{\ddagger}$ and Esther Hauk ${ }^{\S}$
}

April 2009

\begin{abstract}
In the presence of cost uncertainty, limited liability introduces the possibility of default in procurement with its associated bankruptcy costs. When financial soundness is not perfectly observable, we show that incentive compatibility implies that financially less sound contractors are selected with higher probability in any feasible mechanism. Informational rents are associated with unsound financial situations. By selecting the financially weakest contractor, stronger price competition (auctions) may not only increase the probability of default but also expected rents. Thus, weak conditions are sufficient for auctions to be suboptimal. In particular, we show that pooling firms with higher assets may reduce the cost of procurement even when default is costless for the sponsor.
\end{abstract}

Keywords: Procurement, limited liability, bankruptcy.

JEL classification numbers: L51, H57, D44.

*We thank participants of the Barcelona Jocs seminar for helpful comments and suggestions. All authors acknowledge the support of the Barcelona GSE Research and the government of Catalonia. Hauk acknowledges financial support from the CICYT project n. SEJ2006-01717

†Institut d'Anàlisi Econòmica CSIC, Campus UAB, 08193 Bellaterra, e-mail: roberto.burguet@iae.csic.es

$\ddagger$ Department of Economics and Business, Universitat Pompeu Fabra, Ramon Trias Fargas 23-27, 08005 Barcelona, e-mail: juanjo.ganuza@upf.edu

§Institut d'Anàlisi Econòmica CSIC, Campus UAB, 08193 Bellaterra, e-mail: esther.hauk@iae.csic.es 


\section{Introduction}

The high frequency of bankrupt bidders in high-stake auctions and procurement, especially in the construction industry ${ }^{1}$, has lead researchers to move away from traditional auction theory with deep pocket bidders to analyze the possibility of default. ${ }^{2}$ It is now well understood that limited liability makes bidders risk-loving by cutting off the downside losses. The implied tendency of bidders to bid more aggressively increases the probability of contractors' default. Default or bankruptcy may be costly for the sponsor: it implies delays in the completion of the project, litigation costs, ${ }^{3}$ the cost of the new procurement process, etc. The literature explains why broke bidders are frequent - the poorest bidder is the most aggressive -, compares the performance of different auction formats, ${ }^{4}$ and analyses the possibility of insurance. ${ }^{5}$ However, little is known about the constraints that this possibility of default imposes on the feasible trading mechanisms, or about the optimal

\footnotetext{
${ }^{1}$ In the US during 1990-1997 more than 80,000 contractors went bankrupt leaving unfinished private and public construction projects with liabilities exceeding $\$ 21$ billion (Dun \& Bradstreet Business Failure Record).

${ }^{2}$ Examples are Waehrer (1995), Zheng (2001) and Board (2007) in forward auctions and Calveras et al. (2004) and Engel and Wambach (2006) in procurement auctions.

${ }^{3}$ White (1989) reports direct administrative costs for liquidating a firm in the US for which bankruptcy courts keep record: these make up 7.5\%-21\% of the liquidation proceeds.

${ }^{4}$ Board (2007) shows that if bidders have the same budget but different valuations the second price auction induces higher prices, higher bankruptcy rates and lower utilities than the first price auction. Engel and Wambach (2006) obtain comparable results for a procurement setting. They also provide an illustrative comparison between a second-price auction with a multi-source second-price auction without switching costs and a lottery. Both papers show that the sponsor's preferences over different mechanisms crucially depend on the bankruptcy costs.

${ }^{5}$ Calveras et al. (2004) focus on the regulatory practice of surety bonds (financial collateral) and show that these bonds reduce and sometimes eliminate the problem of abnormally low tenders (low bids with high bankruptcy risk).
} 
mechanism in the presence of limited liability. ${ }^{6}$ The present paper makes a first step in attacking this problem. We analyze procurement with limited liability. Bidder heterogeneity is modeled in terms of financial assets, and therefore in terms of financial robustness, which is private information. ${ }^{7} \mathrm{We}$ study a model with a continuum of types (financial assets), and common uncertainty about the cost of carrying out the contract at the time of signing it. That is, in order to concentrate on the effect of limited liability, we abstract from cost efficiency differences between contractors.

Under these assumptions, and excluding the possibility of payments not associated to awarding the contract, ${ }^{8}$ we show that: (i) the search for the optimal mechanism can be restricted to mechanisms where the price depends only on the type of the winner; (ii) it is enough to consider the win probabilities (or only the prices) that mechanisms assign to each type of bidder when we compare rents and expected costs of different mechanisms (revenue equivalence); (iii) limited liability has a "perverse" effect: incentive compatibility imposes that win probabilities are monotonically decreasing and prices monotonically increasing in the financial assets of the bidders. In

\footnotetext{
${ }^{6}$ Che and Gale (2000) characterize the optimal mechanism for selling to a budgetconstrained buyer. This is equivalent to analyzing the one-bidder no-default case. Pai and Vohra (2008) extend the previous analysis to n-bidders in a discrete type space.

${ }^{7}$ Another strand of the literature (e.g. Waehrer 1995, Engel and Wambach, 2006, Board, 2007) model bidder heterogeneity by assuming equal assets but different valuations / costs. We believe that our approach with different wealth levels is more interesting since as shown by Calveras et al, (2004) and Zheng (2001) it destroys the efficiency properties of auctions and selects the bidder with the lowest assets. Moreover, empirical evidence seems to confirm budgetary issues are an important factor in explaining company failure: Arditi et al. (2002) show that budgetary issues explain $60.2 \%$ of the company failures in the US construction industry.

${ }^{8}$ In this environment it seems reasonable to assume that sponsors cannot use trading mechanism with transfers from losers to the winner or from losers to the sponsor. They are difficult to reconcile with private information on financial assets and limited liability.
} 
other words, in any feasible mechanism and no matter how high bankruptcy costs are, firms in a bad financial situation are at least as likely to be assigned the project as financially solvent firms.

This third result, perhaps the most striking one, is in fact intuitive. Given any contract price, a firm with fewer assets is better protected against bad cost realizations than a more sound firm. Therefore, the former is always willing to trade price for probability of winning if the latter is.

In our setting, an optimal mechanism should combine the goal of reducing informational rents with the need for limiting the inefficiency of the allocation, which requires keeping the bankruptcy probability low. Given the incentive compatibility constraints, the second goal in isolation is achieved by an optimal posted price, which randomly assigns the contract and therefore does not select worse firms with (strictly) higher probability. A more striking result is that, contrary to what could be expected, the first goal in isolation is not necessarily achieved by an auction. Even when bankruptcy costs are negligible (or inexistent), informational rents might not be minimized by a mechanism that minimizes the contracted price by selecting the firm with lowest assets. Informational rents here are associated to "bad" financial states and the probability of default. Then lower contracted prices, which necessarily go hand in hand with higher probabilities of selecting less solvent firms and higher probabilities of default, bolster informational rents. We find sufficient conditions that guarantee that, even with no costs associated to default, auctions are suboptimal mechanisms to assign the contract.

Our results can be put in perspective by relating them to those of Manelli 
and Vincent (1995). That paper characterizes the optimal procurement mechanism in an environment where the valuations of the uninformed buyer over the potential sellers' goods (quality) are positively correlated with the seller's opportunity cost of supplying the good. As in the present paper, auctions or price competition lead to awarding the project to the least preferred supplier and mechanisms with some randomization in the winning probabilities may be optimal. In our setting, bidders with worse financial status are those that would result in higher default probability for the sponsor and then, other things (price) equal, are less attractive if default is costly. Although the relationship is less direct in our case, we can think of this bankruptcy exposure as a sort of lower quality for the sponsor. However, the parallel breaks when we consider that even with no bankruptcy costs price competition might still be undesirable for the sponsor. Indeed, in our model informational rents are more subtle and are linked to the probability of default, whether default is per se costly or not. This probability is higher when price competition is more intense. Thus, even under regularity assumptions on the inverse hazard rate, it may be in the interest of the sponsor to blunt price competition.

We analyze the implications of these results for the design problem of sponsors by considering a discrete (three type) parameterized example. We show that pooling the two higher types may result in a lower cost for the sponsor even when bankruptcy has no associated costs. This could not be achieved by pooling the lower types. We also show that these insights extend to a general $K$ type space. This example lends some justification for blunting 
price competition in the presence of limited liability even for low costs of default, but raises questions about the right way to do so.

The remainder of the paper is organized as follows. In section 2 we present the model. Section 3 contains our main results for the continuous type model. In section 4 we relate our results to those of Manelli and Vincent (1995) and offer conditions that make auctions suboptimal even in the absence of default costs. We also study a discrete parameterized example to investigate the types of mechanisms that may be more appropriate in these cases. Section 5 concludes. All proofs are relegated to a technical appendix.

\section{The Model}

A risk neutral buyer (sponsor) procures an indivisible contract for which he is willing to pay $V$, which we assume large enough as to make the possibility of no contracting unattractive. There are $N$ risk-neutral potential contractors all with the same cost, $c$, unknown at the time of signing the contract. Thus, $c$ is a random shock which we assume to be uniformly distributed on $[0,1]$. Potential contractors differ in their initial financial status. Let $A_{i} \geq 0$ denote the value of the assets of potential contractor $i=1,2, \ldots, N$. $A_{i}$ is private information of firm $i$. Each $A_{i}$ is an independent realization of a random variable with support $[\underline{A}, \bar{A}]$, density function $f(\cdot)$, and distribution $F(\cdot)$.

Without loss of generality, we can restrict attention to the case $\bar{A} \leq \frac{1}{2}$. As will become clear below, a firm with assets above $\frac{1}{2}$ will never default, and as a consequence any such firm would behave (and would have to be treated) as a firm with assets $\frac{1}{2}$. We denote by $A$ the vector of firms' types, 
$A=\left(A_{1}, A_{2}, \ldots, A_{N}\right){ }^{9}$

Contractors have limited liability, i.e. the losses of firm $i$ cannot be larger than $A_{i}$. Therefore, when awarded the project firm $i$ will close down if $A_{i}$ plus the net profits from undertaking the project fall below 0 once $c$ is realized.

The sponsor chooses a procurement process to award the contract. After the contract is awarded at a price $P$, the cost $c$ is realized and the selected contractor either finishes the project or declares bankruptcy. Bankruptcy may imply extra costs for the sponsor. We summarize these costs by a constant $C_{B}$, with $C_{B} \geq 0$. Thus, when the selected contractor declares bankruptcy the sponsor has to bear the realized cost $c$ plus this bankruptcy cost, but can liquidate and seize the assets of the firm, $A_{i}$ (together with whatever payment he had made, $P$ ). Thus, if the sponsor signs a contract with firm $i$ (with assets $A_{i}$ ) at a price $P$ and the realized cost is $c$, then the utility of the sponsor is

$$
U^{S}= \begin{cases}V-P & \text { if } P-c+A_{i} \geq 0 \\ V-c+A_{i}-C_{B} & \text { otherwise }\end{cases}
$$

These payoffs can be considered the reduced form payoffs of a continuation game where the sponsor asks for bids from the rest of contractors once the realized cost $c$ has been revealed.

Note that we are implicitly assuming that the sponsor cannot use trading mechanisms with transfers from losers to the winner and/or the sponsor. Besides being unrealistic, such (meaningful) trading mechanisms would be difficult to reconcile with limited liability and private information on financial

\footnotetext{
${ }^{9}$ This way of modeling bidder-heterogeneity is due to Che and Gale (1996) who model bidder-heterogeneity in terms of wealth instead of value in a forward auction. It is also used in Zheng (2001).
} 
assets.

We now summarize the timing of the model:

1. Nature chooses the financial value $A_{i}$ of each firm. Each firm privately learns its financial assets.

2. The sponsor announces the procurement process.

3. Firms submit their "bids" or messages, and the project is awarded according to the rules announced by the sponsor. The price $P$ is set according to these rules.

4. The cost parameter $c$ is realized. If the assets of the selected firm $i$ are such that $A_{i}+P-c \geq 0$, then the firm finishes the project. Otherwise it declares bankruptcy.

5. The sponsor and the firms realize their payoffs. The selected firm retains a financial value of $\max \left\{0, A_{i}+P-c\right\}$, all other firms retain their assets, and the contractor obtains a payoff defined in (1).

\section{Implementable mechanisms}

We restrict attention to trading mechanisms where prices are deterministic after conditioning on all types, $A$, and the identity of the winner. Thus, we allow for mechanisms such as the second price auction, but we do not consider mechanisms where the sponsor uses random devices that are not related to the primitives of the problem to (partially) determine the price. Thus, a mechanism is a pair $(\sigma, P)$, where $P:[\underline{A}, \bar{A}]^{N} \rightarrow R^{N}$, and $\sigma:$ 
$[\underline{A}, \bar{A}]^{N} \rightarrow \Delta^{N}$. We interpret $\sigma_{i}(A)$ as the probability that supplier $i$ is assigned the project when $A$ is the vector of assets, and $P_{i}(A)$ as the price of the contract if the vector of assets (types) is $A$ and supplier $i$ is assigned the project. Incentive compatibility, IC, in this setting means that for all $A_{i}$ and $\widehat{A}_{i}$, and all $i,{ }^{10}$

$$
\begin{aligned}
& E_{A_{-i}} \sigma_{i}(A)\left[\int_{0}^{\min \left\{1, P_{i}(A)+A_{i}\right\}}\left(P_{i}(A)+A_{i}-c\right) d c-A_{i}\right] \geq \\
& E_{A_{-i}} \sigma_{i}\left(A_{-i}, \widehat{A}_{i}\right)\left[\int_{0}^{\min \left\{1, P_{i}\left(A_{-i}, \widehat{A}_{i}\right)+A_{i}\right\}}\left(P_{i}\left(A_{-i}, \widehat{A}_{i}\right)+A_{i}-c\right) d c-A_{i}\right] .
\end{aligned}
$$

This is one of the constraints on the sponsor's choice. The sponsor also faces individual rationality constraints, IR: for all $i$ and for all $A_{i}$,

$$
U_{i}\left(A_{i} ; \sigma, P\right) \equiv E_{A_{-i}} \sigma_{i}(A)\left[\int_{0}^{\min \left\{1, P_{i}(A)+A_{i}\right\}}\left(P_{i}(A)+A_{i}-c\right) d c-A_{i}\right] \geq 0 .
$$

The sponsor's goal is to minimize the cost of the project. That is, to minimize

$$
E_{A} \sum_{i} \sigma_{i}(A)\left[P_{i}(A)+\int_{\min \left\{1, P_{i}(A)+A_{i}\right\}}^{1}\left(c+C_{B}-P_{i}(A)-A_{i}\right) d c\right] .
$$

First we show that the sponsor needs to consider only mechanisms where the price depends on the type and identity of the winner, but not on the types of other bidders.

Lemma 1 For any IC, IR mechanism $(\sigma, P)$, there exists a mechanism $(\sigma, \bar{P})$, where $\bar{P}_{i}(A)$ is constant on $A_{-i},(\sigma, \bar{P})$ is also IC and IR, results in the same expected rents for each firm $i$ and each value of $A_{i}$, and results in expected (weakly) lower cost for the sponsor.

\footnotetext{
${ }^{10}$ Note that we are implicitly assuming that bankruptcy cannot be claimed when funds are sufficient to cover the cost. That is, that assets cannot be hidden once the supplier has applied for bankruptcy.
} 
Proof. See appendix.

From now on we will only consider mechanism where the payments are independent of types other than that of the winner. Thus, let us define $\Psi_{i}\left(A_{i}\right)=E_{A_{-i}} \sigma_{i}(A) . \Psi_{i}\left(A_{i}\right)$ is the expected probability that bidder $i$ obtains the contract when conditioning on its information, $A_{i}$. Incentive compatibility implies a crucial monotonicity property of trading mechanisms. Indeed,

Lemma 2 If $(\sigma, P)$ is IC, then $U_{i}\left(A_{i} ; \sigma, P\right)$ is continuous and monotone decreasing in $A_{i}$. Monotonicity is strict if $1>P_{i}\left(A_{i}\right)+A_{i}$.

Proof. See appendix.

Lemma 2 implies that informational rents are linked to low asset holdings, not to solvency. This monotonicity result also implies monotonicity of allocation and prices. This is our most important result.

Lemma 3 In any IC mechanism $\Psi_{i}\left(A_{i}\right)$ is monotonically decreasing and $P\left(A_{i}\right)$ monotonically increasing.

Proof. See appendix.

Lemma 3 unveils the "perverse effects" of limited liability. By cutting off the downside losses, limited liability makes firms risk-loving. The fewer assets a firm has, the stronger is this effect. Firms with many assets will be more conservative since they have more to lose. Therefore, they are only willing to procure the project at higher prices. Firms with fewer assets can imitate firms with higher assets and will only be stopped from doing so and accept a lower price if this increases their win probabilities. In other words, even when choosing the procurement mechanism optimally firms in a bad 
financial situation are at least as likely to win the project as more solvent firms. Indeed, from continuity and monotonicity, $U_{i}\left(A_{i} ; \sigma, P\right)$ is differentiable almost everywhere if it is bounded. It is bounded from below by IR and can be bounded above in a search for an optimal mechanism. Now, let $U_{i}$ be differentiable at $A_{i}$. Applying the envelope theorem, the derivative of $U_{i}$ at $A_{i}$ is

$$
-\left[1-\left(P_{i}\left(A_{i}\right)+A_{i}\right)\right] \Psi_{i}\left(A_{i}\right) .
$$

when $P_{i}\left(A_{i}\right)+A_{i}<1$, and zero otherwise. Recall that $\left[1-\left(P_{i}\left(A_{i}\right)+A_{i}\right)\right]$ is the probability that firm $i$ defaults if assigned the contract. Thus, the source of informational rents is the probability of default. This allows us to obtain a "revenue equivalence" result in this setting.

Lemma 4 Two mechanisms that share $\Psi_{i}\left(A_{i}\right)$ and give the same rents to bidders of the highest type also share $P_{i}\left(A_{i}\right)$.

Proof. See appendix

Thus, we need only consider $\Psi_{i}\left(A_{i}\right)$, i.e., $\sigma$, when we compare rents and expected costs of two different mechanisms.

We can write the expected payment for the sponsor as the sum of the expected cost of the project, expected utility payments and expected bankruptcy costs.

$$
c+\sum_{i} E_{A} U_{i}\left(A_{i} ; \sigma, P\right)+E_{A} \sum_{i} \sigma_{i}(A)\left[1-\left(P_{i}\left(A_{i}\right)+A_{i}\right)\right] C_{B}
$$

On the other hand, from (3)

$$
U_{i}\left(A_{i} ; \sigma, P\right)=U_{i}(\bar{A} ; \sigma, P)+\int_{A_{i}}^{\bar{A}}\left[1-\left(P_{i}(x)+x\right)\right] \Psi_{i}(x) d x .
$$


Using this equation we can write

$$
E_{A_{i}} U_{i}\left(A_{i} ; \sigma, P\right)=U_{i}(\bar{A} ; \sigma, P)+E_{A} \int_{A_{i}}^{\bar{A}} \sigma_{i}\left(A_{-i}, x\right)\left[1-\left(P_{i}(x)+x\right)\right] d x .
$$

Hence we can rewrite (4) as:

$$
\begin{aligned}
& c+\sum_{i} U_{i}(\bar{A} ; \sigma, P)+ \\
& \sum_{i} E_{A_{i}}\left[\int_{A_{i}}^{\bar{A}} \Psi_{i}(x)\left[1-\left(P_{i}(x)+x\right)\right] d x+\Psi_{i}(x)\left[1-\left(P_{i}\left(A_{i}\right)+A_{i}\right)\right] C_{B}\right] .
\end{aligned}
$$

Notice that the third term of this expression captures the informational rents and the bankruptcy costs incurred. This third term can be written as

$\sum_{i} \int_{0}^{\bar{A}}\left[\int_{A_{i}}^{\bar{A}} \Psi_{i}(x)\left[1-\left(P_{i}(x)+x\right)\right] d x+\Psi_{i}\left(A_{i}\right)\left[1-\left(P_{i}\left(A_{i}\right)+A_{i}\right)\right] C_{B}\right] f\left(A_{i}\right) d A_{i}$

or, changing the order of integration,

$$
\begin{aligned}
& \sum_{i} \int_{0}^{\bar{A}} \Psi_{i}\left(A_{i}\right)\left[1-\left(P_{i}\left(A_{i}\right)+A_{i}\right)\right]\left(\frac{F\left(A_{i}\right)}{f\left(A_{i}\right)}+C_{B}\right) f\left(A_{i}\right) d A_{i} \\
= & \sum_{i} \int_{0}^{\bar{A}} E_{A_{-i}} \sigma_{i}(A)\left[1-\left(P_{i}\left(A_{i}\right)-c+A_{i}\right)\right]\left(\frac{F\left(A_{i}\right)}{f\left(A_{i}\right)}+c_{B}\right) f\left(A_{i}\right) d A_{i} \\
= & E_{A} \sum_{i} \sigma_{i}(A)\left[1-\left(P_{i}\left(A_{i}\right)+A_{i}\right)\right]\left(\frac{F\left(A_{i}\right)}{f\left(A_{i}\right)}+C_{B}\right) .
\end{aligned}
$$

We know from Lemma 3 that $P_{i}\left(A_{i}\right)$ is monotonically increasing, hence $P_{i}\left(A_{i}\right)+A_{i}$ also increases in $A_{i}$. Therefore, the probability of default, namely $\max \left[0,1-\left(P_{i}\left(A_{i}\right)+A_{i}\right)\right]$ decreases in $A_{i}$. So lower types are always associated with higher bankruptcy costs. It is not so clear what happens with informational rents since $\left[1-\left(P_{i}\left(A_{i}\right)+A_{i}\right)\right] \frac{F\left(A_{i}\right)}{f\left(A_{i}\right)}$ might not be monotone even under the assumption that the inverse hazard rate is monotonically increasing.

On the other hand, by the individual rationality constraint $U_{i}(\bar{A} ; \sigma, P) \geq$ 0 . Since the highest type has no incentive problems to reveal its type, one 
may expect that the optimal mechanism assigns zero rents to this type. However, $U_{i}(\bar{A} ; \sigma, P)$ also determines the probability of default, hence it also affects bankruptcy costs. Thus, it might be worthwhile to leave some rents to the highest type if this reduces the probability of default sufficiently and bankruptcy costs are high. To see this assume that $C_{B} \rightarrow \infty$. In this case it is optimal to avoid bankruptcy altogether, which can be achieved only if $P_{i}(\underline{A})+\underline{A} \geq 1$, which in turn implies that $P_{i}(\bar{A})+\bar{A}>1$, so that, by IC, $U_{i}(\bar{A})>0$.

\section{Implications for the design of optimal mech- anisms}

From now on we can dispense with the subscript that refers to a particular bidder. The problem we have been analyzing shares some important features with the problem studied by Manelli and Vincent (1995). In their paper,

suppliers with cost (type) $c$ supply a good of unobservable quality $v(c)$. If the buyer trades with a supplier with $\operatorname{cost} c$ at a price $P$, then the buyer's surplus is $v(c)-c-\pi$. Given $\pi$, and assuming that $v(c)-c$ is increasing in $c$, the buyer prefers high type $c$ suppliers. However, IC also imposes that the probability of trade is non increasing in $c$. In our problem, we could denote the probability of non-default by $\alpha$, and define a transformed willingness to pay for the project as $V^{\prime}=V-(1-\alpha) C_{B}$. If the buyer trades with a type $A$ supplier, the buyer's surplus is $V^{\prime}-\pi-E c$. Since $\alpha=\max \{(P+A), 1\}$ is increasing in $A$, we have that when $C_{B}>0, V^{\prime}$ is increasing in the type $A$ just as in Manelli and Vincent (1995). Moreover, IC also implies that the 
probability of trade is non increasing in $A$. Thus, our results can be read in the light of Manelli and Vincent: price competition selects bad types, and then it may be in the interest of the buyer to avoid it. Limited liability and private information about the financial state introduce some sort of quality differential correlated to the bidders' privately known willingness to supply.

However, this is where the parallel stops. Indeed, the interaction between price competition and the buyer's surplus is complicated by the dependency of $\alpha$ on $A$ and $P$. While informational rents can be represented by the inverse hazard rate in Manelli and Vincent (1995), in our problem this term is

$$
(1-\alpha) \frac{F(A)}{f(A)}=[1-(P(A)+A)] \frac{F(A)}{f(A)} .
$$

Put in other terms, $U_{i}^{\prime}=-(1-\alpha) \Psi(A)$. Thus, apart from the direct effect that a change in $\Psi(A)$ (and so in $P$ ) has on the rents of suppliers, it also has an indirect effect through its effect on the probability of default $(1-\alpha)$. As a result, even if the inverse hazard rate is monotone, it may well be that $(1-\alpha) \frac{F(A)}{f(A)}$ (which depends on the mechanism itself) is not. In this case, even if the default $\operatorname{cost} C_{B}$ is zero, so that $V^{\prime}$ is independent of the supplier's type, the optimal mechanism does not need to be one that selects the lowest type. That is, an auction needs not be that optimal mechanism. The following Lemma shows that under weak conditions an auction will be suboptimal.

Lemma 5 For any $C_{B} \geq 0$, there exist non strictly monotone, IC mechanisms that result in higher surplus for the buyer than mechanisms that assign the contract to the bidder with lowest $A$ (auctions) if $f^{\prime}(A)$ exists and is negative for $A$ close to $\bar{A}$. 
Proof. See appendix.

It is not difficult to understand this possibility. Increasing the probability that higher types win the contract by, say, pooling a certain interval of types, the mechanism not only results in a higher contract price: it also results in a higher expected value of the assets of the winner. Thus, it increases the probability that the contract price will coincide with the realized cost for the sponsor. In contrast, the auction selects the contractor with lowest assets, so that although it minimizes the contract price it also maximizes the probability that the realized cost for the sponsor exceeds that price.

We can further investigate the type of simple mechanisms that may be optimal from the point of view of the sponsor by substituting a discrete type space for the continuous type space that we have been assuming up to this point. In particular, assume that $A$ can take on three values, $A_{k}$, $k=0,1,2$, and for simplicity assume that $A_{0}=0, A_{1} \in\left(0, \frac{1}{2}\right)$ and $A_{2}=\frac{1}{2}$. We denote the probability of the three types, respectively as $\alpha_{0}, \alpha_{1}$, and $\alpha_{2}=1-\left(\alpha_{0}+\alpha_{1}\right)$. Also for simplicity, we will assume that there are only two bidders. It will become clear below that none of these assumptions, not even the three-type assumption, are restrictive.

A mechanism in this setting can be represented by a set of six values, $\left(\Psi_{0}, \Psi_{1}, \Psi_{2}\right)$ and $\left(P_{0}, P_{1}, P_{2}\right)$ that denote the probability of winning and the price for each of the three types. Notice that we are only considering symmetric mechanisms. Also, notice that $\Psi_{k}$ is positive for all $k$, since in case both bidders draw the same type each is assigned the contract with probability half (the contract is always allocated). That is, $\Psi_{k} \geq \frac{\alpha_{k}}{2}$. Then, individual 
rationality for type 2 amounts to $P_{2} \geq 1 / 2$. The fact that the probability of allocation is one also eliminates one degree of freedom in the choice of $\Psi_{k}$. Then, the sponsor's problem is to choose four values (say $\Psi_{0}, \Psi_{1}, P_{0}, P_{1}$ ) to minimize the cost of the contract. The (other) constraints that the sponsor faces are the incentive compatibility constraints for types 0 and 1, and monotonicity of $\Psi_{k}$ together with the conformity of $\Psi$ with some probability $\sigma$

These are the elements that define the problem for the sponsor whose solution is the optimal mechanism. For now, let us consider a simpler question: would a mechanism that selects the lowest type with probability one and then guarantees the lowest expected contract price be always optimal for the sponsor if $C_{B}=0$ ? Or else, would the sponsor prefer to pool some of the types even when there are no costs associated to bankruptcy?

Thus, we assume away bankruptcy costs, $C_{B}=0$, in which case the goal for the sponsor is to minimize $\sum_{k=1}^{3} \alpha_{k} U\left(A_{k}\right)$. We begin by comparing a mechanism that assigns the contract to the lowest type to one where the two higher types are pooled. That is, a mechanism with $\Psi_{0}=\left(1-\frac{\alpha_{0}}{2}\right)$ and $\Psi_{1}=\left(1-\alpha_{0}-\frac{\alpha_{1}}{2}\right)$ with one with $\Psi_{2}^{P}=\Psi_{1}^{P}=\frac{1-\alpha_{0}}{2}$. Note that in this latter case $P_{2}^{P}=P_{1}^{P}=1 / 2$, and that only the incentive compatibility for type 0 will bind. That constraint can be written as

$$
\left(1-\frac{\alpha_{0}}{2}\right) \int_{0}^{P_{0}}\left(P_{0}-c\right) d c \geq \frac{1-\alpha_{0}}{2} \int_{0}^{1 / 2}\left(\frac{1}{2}-c\right) d c
$$

or

$$
U^{P}\left(A_{0}\right)=\left(1-\frac{\alpha_{0}}{2}\right) \frac{P_{0}^{2}}{2} \geq \frac{1-\alpha_{0}}{2} \frac{1}{8}
$$

which at the optimum (among such mechanisms) is satiated. Therefore (6) 
with equality determines the rents of a type 0 bidder in such mechanism. On the other hand, the rents for type 1 are

$$
U^{P}\left(A_{1}\right)=\frac{1-\alpha_{0}}{2}\left(\int_{0}^{\frac{1}{2}+A_{1}}\left(\frac{1}{2}+A_{1}-c\right) d c-A_{1}\right)=\frac{1-\alpha_{0}}{2}\left(\frac{\left(\frac{1}{2}+A_{1}\right)^{2}}{2}-A_{1}\right) .
$$

Since (6) is satiated and type 2 expects no rents, the expected rents for a bidder are

$$
\sum_{k=1}^{3} \alpha_{k} U^{P}\left(A_{k}\right)=\alpha_{0} \frac{1-\alpha_{0}}{2} \frac{1}{8}+\alpha_{1} \frac{1-\alpha_{0}}{2}\left(\frac{\left(\frac{1}{2}+A_{1}\right)^{2}}{2}-A_{1}\right) .
$$

Let us turn to a mechanism that assigns the contract to the lowest type. It will have to guarantee incentive compatibility for the two lower types. That is

$$
U\left(A_{0}\right)=\left(1-\frac{\alpha_{0}}{2}\right) \frac{P_{0}^{2}}{2} \geq\left(1-\alpha_{0}-\frac{\alpha_{1}}{2}\right) \frac{P_{1}^{2}}{2},
$$

for type 0 , and

$$
U\left(A_{1}\right)=\left(1-\alpha_{0}-\frac{\alpha_{1}}{2}\right)\left[\frac{\left(P_{1}+A_{1}\right)^{2}}{2}-A_{1}\right] \geq \frac{1-\alpha_{0}-\alpha_{1}}{2}\left(\frac{\left(\frac{1}{2}+A_{1}\right)^{2}}{2}-A_{1}\right),
$$

for type 1. Again, notice that there is no reason to leave any slack, so that both constraints will be satiated at the optimal (in this restricted set) mechanism. Therefore, (9) with equality determines $P_{1}$, and then (8) with equality determines $P_{0}$. As a function of $P_{1}$ defined implicitly by (9) with equality, the expected rents in this mechanism are

$$
\sum_{k=1}^{3} \alpha_{k} U\left(A_{k}\right)=\alpha_{0}\left(1-\alpha_{0}-\frac{\alpha_{1}}{2}\right) \frac{P_{1}^{2}}{2}+\alpha_{1} \frac{1-\alpha_{0}-\alpha_{1}}{2}\left(\frac{\left(\frac{1}{2}+A_{1}\right)^{2}}{2}-A_{1}\right) .
$$

Notice that $U^{P}\left(A_{1}\right)>U\left(A_{1}\right)$. Indeed, the probability that type 2 obtains the contract is larger in the pooled mechanism and the price in both mechanisms is the same for this type. Since type 1 obtains its rents from 
the possibility of imitating type 2 bidder, its rents must be larger in the pooled mechanism. This argument is independent on the number of types and in particular of the existence of type 0 . This immediately implies that with $C_{B}=0$ the optimal mechanism with only two possible types must minimize the probability that the high type obtains the contract, i.e., assign the contract to the lowest type.

However, in a three type case pooling the two largest types reduces the probability that type 1 obtains the contract, and therefore the probability that type 0 still obtains the contract if it decides to imitate type 1 . Since this possibility of imitation is the source of rents for type 0 (i.e., since (8) holds with equality), and since type 0 is mainly interested in the probability of obtaining the contract, this pooling of the two high types reduces the rents of type 0 bidder. Whether or not the mechanism that pools the two highest types does better than the one that assigns the contract to the lowest type depends on which of the two effects dominates. We now provide examples for both cases.

Example 1 Assume that $\alpha_{0}=.8, \alpha_{1}=.1$, and $A_{1}=.1$. In this case, the price $P_{1}$ defined implicitly by (9) is 0.403322 in the mechanism that assigns the contract to the lowest type. The rents for type 0 are $9.76 \times 10^{-3}$, and the rents for type 1 are $4 \times 10^{-4}$. Total expected rents in this mechanism are $1.016 \times 10^{-2}$. In the pooled mechanism, the rents for type 0 are 0.01 and for type 1 are $8 \times 10^{-4}$ so that total expected rents are $1.08 \times 10^{-2}$.

Example 2 Assume that $\alpha_{0}=.1, \alpha_{1}=.1$, and $A_{1}=.3$. In this case, the price $P_{1}$ defined implicitly by (9) is 0.48665 in the mechanism that assigns the 
contract to the lowest type. The rents for type 0 are 0.10065 , and the rents for type 1 are $7.9977 \times 10^{-3}$. Thus total expected rents in this mechanism are $1.0865 \times 10^{-2}$. In the pooled mechanism, the rents for type 0 are 0.05625 and for type 1 are 0.009 so that the expected rents are $6.525 \times 10^{-3}$.

Thus, pooling of the two highest types may reduce informational rents and the resulting expected price for the sponsor. Could this be attained by pooling the two lower types instead? The answer is in the negative. Indeed, if the two low types are pooled, then type 1 would still expect the same rents, whose source would be the possibility of imitating the unaffected high type 2 bidder. Moreover, these rents would now come from an increased probability of obtaining the contract and a lower price. If that trade off leaves type 1 indifferent, then an imitating type 0 will prefer the higher probability. Thus, the rents of type 0 would certainly be higher in the mechanism that pools the two low types. Moreover, this effect of pooling the two low types is independent of whether type 1 is itself pooled to type 2 or not. That is, total pooling (a posted price $P=\frac{1}{2}$ ) always leaves more rents to contractors than a mechanism that only pools the two high types. ${ }^{11}$

Do these insights extend to a general, $K$ type case? The answer is in the positive. Indeed, pooling the two lowest types could never be optimal. To see this, assume that there are additional types $A_{2}, A_{3} \ldots, A_{K}$, with $A_{k}>A_{k-1}$. If the win probability of the other types $k>1$ is unaffected, then pooling

\footnotetext{
${ }^{11}$ Indeed, in the former the rents of type 1 would be higher: they would still be given by the right hand side of (7) with only substituting $\frac{1}{2}$ for $\frac{1-\alpha_{0}}{2}$. But the rents of type 0 would also be higher. They would still be given by the right hand side of (6) also substituting $\frac{1}{2}$ for $\frac{1-\alpha_{0}}{2}$. That is, not only the win probability of type 2 would be higher, but also the win probability of type 1 , the one that could be imitated by type 0 .
} 
of types 0 and 1 (and consequently, changing both $P_{0}$ and $P_{1}$ so that the IC constraints for these types still hold with equality), would result in the same rents for type 1: once more, its rents would equal those obtained by imitating type 2 , for which the mechanism would still look the same. However, these rents would now be obtained with a higher value $\Psi_{1}$ and a lower value $P_{1}$. So the rents for type 0 will be higher. Thus, for arbitrary discrete type spaces we conclude that pooling the lowest types will never be optimal when $C_{B}=0$. A trivial corollary is that total pooling will never be optimal either under these circumstances.

Similarly, for arbitrary discrete type spaces, pooling of the two highest types will always increase the rents of the second highest type (the value of $\Psi_{K}$ goes up and $P_{K}$ remains unchanged, determined by the IR constraint for type $K$, so that by imitating type $K$ type $K-1$ can guarantee higher rents). However, every other type below $K-1$ will see its rents reduced. On the one hand, the values of $\Psi_{k}$ for $k<K-1$ are unaffected. On the other hand, using exactly the same argument used in the three type case for type 0 , the rents for type $K-2$ will be lower, which means that $P_{K-2}$ is also lower. Iterating this argument, we conclude that $P_{k}$ will be lower for all types $k<K-1$. That is, the possibility of reducing rents by pooling the higher types is not particular to the three types case.

What this discussion tells us is that a price ceiling (obtained, for instance, by a floor in the score assigned to price offers, coupled with a price ceiling as such) may be desirable in a procurement mechanism in this setting, but a (binding) price floor often used by public administrations will never be. ${ }^{12}$

\footnotetext{
${ }^{12}$ Once we have pooled the two lowest types, we could consider pooling the third lowest
} 
Not surprisingly, as the cost of bankruptcy $C_{B}$ increases, pooling of types becomes even more attractive. Also, the relative impact of pooling at the top and at the bottom becomes less clear cut. Indeed, our discussion above has shown that pooling at the top increases the price (and thereby decreases the probability of default) for the pooled types but reduces all prices (and hence increases the probability of bankruptcy) for lower types. This latter effect is absent when pooling at the bottom. However, the prices of the pooled types move in different directions. Indeed, the higher of the types pooled now has a higher probability of obtaining the contract, and therefore sees its price reduced (and hence its probability of default increased). However, the price for the lowest type who now has lower probability of obtaining the contract but has to be guaranteed higher rents, must increase (and consequently its probability of default must decrease). It is not difficult to construct examples where one or the other partial pooling is more effective in reducing the probability of default. ${ }^{13}$ Of course, complete pooling unambiguously reduces the probability of default. Thus, when $C_{B}$ is large enough, complete pooling, i.e. posted prices, are optimal mechanisms for assigning the contract.

type as well. The argument used to show that pooling the two lowest types increases the rents of contractors shows that this could only further increase the contractors' expected rents. Thus, a price floor, whether it only pools the two lowest types or some larger set of types at the bottom, is never optimal.

${ }^{13}$ For instance, in our example 2 above, pooling at the bottom reduces this probability of default more than pooling at the top. But if we change the value of $A_{0}$ to .1 then the opposite is true. 


\section{Conclusions}

We have shown that limited liability may introduce a perverse selection in procurement when the cost of the project is common but uncertain, and firms differ in their financial strength. Indeed, in this case incentive compatibility implies that selecting the more sound firm is not feasible. In fact, the stronger the price competition the more likely it is to select the financially weakest firm. This is an unfortunate aspect of price competition when the costs of default are high. Perhaps more surprisingly, even if these costs are inexistent, fiercer price competition, and so a higher likelihood of selecting financially weaker firms, may be against the interest of the sponsor. Indeed, informational rents, and not only default costs, are linked to the probability of default. Thus, mechanisms that give rise to higher probability of default may also result in higher informational rents. We have provided sufficient conditions under which the sponsor will always prefer to curtail price competition somehow when the space of types is a continuum. These are far from necessary. By considering a finite type space, we have argued that limited liability may give some foundations to the usual practice in public procurement of blunting price competition even if default costs are low. However just what sort of limits to price competition are appropriated is a delicate issue. For instance, our discussion shows that price floors, which are commonly used by some public procurers and tend to pool firms at the lower levels of financial strength, may be counterproductive. ${ }^{14}$

\footnotetext{
${ }^{14}$ Another mechanism that is commonly used to limit price competition is the average bid auction in which the bidder closest to the average bid wins. Decarolis (2008) provides empirical evidence using data on the road construction Industry in Italy that the average
} 
Our analysis has abstracted from efficiency differentials. Allocational efficiency is usually appropriately managed by price competition. Thus, our results should be handled with care. When efficiency differentials are suspected to be important, one needs to search for the optimal balance between the two goals of selecting the most efficient firm and the financially fittest. This is an issue left for further research.

\section{Appendix}

Lemma 1 For any IC, IR mechanism $(\sigma, P)$, there exists a mechanism $(\sigma, \bar{P})$, where $\bar{P}_{i}(A)$ is constant on $A_{-i},(\sigma, \bar{P})$ is also IC and IR, results in the same expected profits for each firm $i$ and each value of $A_{i}$, and results in (weakly) expected lower cost for the sponsor.

Proof. Given $A_{i}$, and for all $A_{-i}$, and slightly abusing notation, define $\bar{P}_{i}(A) \equiv \bar{P}_{i}\left(A_{i}\right)$ as the solution to the following equation in $\bar{P}$

$$
\begin{aligned}
& E_{A_{-i}} \sigma_{i}(A) \int_{0}^{\min \left\{1, \bar{P}+A_{i}\right\}}\left(\bar{P}+A_{i}-c\right) d c= \\
& E_{A_{-i}} \sigma_{i}(A) \int_{0}^{\min \left\{1, P_{i}(A)+A_{i}\right\}}\left(P_{i}(A)+A_{i}-c\right) d c .
\end{aligned}
$$

This number exists. Indeed, for $\bar{P} \neq 1$, the derivative of the left hand side with respect to $\bar{P}$ is $E_{A_{-i}} \sigma_{i}(A) \int_{0}^{\min \left\{1, \bar{P}+A_{i}\right\}} d c \geq 0$. Also, for $\bar{P}=-A_{i}$ the left hand side takes a value of 0 , whereas for $\bar{P}=\sup _{A_{-i}} P_{i}(A)$ it takes a value (weakly) larger than the right hand side. Thus, IR implies that $\bar{P}_{i}\left(A_{i}\right)$ exists and is unique. IR and IC follow trivially. Thus, we only need to prove the last claim, namely that the expected cost with $\sigma, \bar{P}$ is lower. Let

bid auctions have generated both significant inefficiencies in contract's allocation and high costs of procurement. 
$C\left(\sigma^{\prime}, P^{\prime}\right)$ represent this expected cost for an arbitrary mechanism $\left(\sigma^{\prime}, P^{\prime}\right)$. Then, substituting the definition of $\bar{P}$, note that

$$
\begin{aligned}
& C(\sigma, P)-C(\sigma, \bar{P})= \\
& C_{B} \sum_{i} E_{A_{i}}\left\{E_{A_{-i}} \sigma_{i}(A)\left[\left(1-\min \left\{1, P(A)+A_{i}\right\}\right)-\left(1-\min \left\{\left(1, \bar{P}\left(A_{i}\right)+A_{i}\right\}\right)\right]\right\}\right.
\end{aligned}
$$

If $\bar{P}\left(A_{i}\right)+A_{i} \geq 1$ this is nonnegative. Assume that $\bar{P}\left(A_{i}\right)+A_{i} \leq 1$ and $P(A)+A_{i} \leq 1$ for all $i$ and all $A$. Then

$$
C(\sigma, P)-C(\sigma, \bar{P})=c_{B} \sum_{i} E_{A_{i}}\left\{E_{A_{-i}} \sigma_{i}(A)\left[\bar{P}\left(A_{i}\right)-P(A)\right]\right\} .
$$

But in this case, from the definition of $\bar{P}$,

$$
E_{A_{-i}} \sigma_{i}(A)\left(\bar{P}\left(A_{i}\right)+A_{i}\right)^{2}=E_{A_{-i}} \sigma_{i}(A)\left(P_{i}(A)+A_{i}\right)^{2} .
$$

Note that if we define $\mu_{-i}$ as $\mu\left(A_{-i}\right)=\frac{1}{E_{A_{-i}} \sigma_{i}(A)} \sigma_{i}\left(A_{-i}, A_{i}\right)$, a density that measures the probability that other suppliers have types $A_{-i}$ and supplier $i$ obtains the contract conditional on supplier $i$ 's type and on supplier $i$ obtaining the project, then

$$
\begin{aligned}
E_{A_{-i}} \sigma_{i}(A)\left(P_{i}(A)+A_{i}\right)^{2} & =E_{A_{-i}} \sigma_{i}(A) \cdot\left[E_{\mu_{-i}}\left(P_{i}(A)+A_{i}\right)^{2}\right] \\
& =E_{A_{-i}} \sigma_{i}(A) \cdot\left[\operatorname{Var}_{\mu_{-i}} P_{i}(A)+\left[E_{\mu_{-i}} P_{i}(A)+A_{i}\right]^{2}\right] .
\end{aligned}
$$

and similarly,

$$
\begin{aligned}
E_{A_{-i}} \sigma_{i}(A)\left(\bar{P}\left(A_{i}\right)+A_{i}\right)^{2} & =E_{A_{-i}} \sigma_{i}(A) \cdot\left[\operatorname{Var}_{\mu_{-i}} \bar{P}\left(A_{i}\right)+\left[E_{\mu_{-i}} \bar{P}\left(A_{i}\right)+A_{i}\right]^{2}\right] \\
& =E_{A_{-i}} \sigma_{i}(A) \cdot\left[\bar{P}\left(A_{i}\right)+A_{i}\right]^{2}
\end{aligned}
$$

since $\bar{P}\left(A_{i}\right)$ is non random in $A_{-i}$. Since $\operatorname{Var}_{\mu_{-i}} P_{i}(A) \geq 0$, we conclude that $\bar{P}\left(A_{i}\right) E_{A_{-i}} \sigma_{i}(A) \geq E_{A_{-i}} \sigma_{i}(A) P(A)$. A similar argument can be used when 
$\bar{P}\left(A_{i}\right)+A_{i} \leq 1$ and $P(A)+A_{i}>1$ for some $i$ and all $A$. (Note that it could not happen for all $A$.) In this case, and for each $A_{i}$, we can divide the support of $A_{-i}$ in two sets, one where $P(A)$ is larger than $1-A_{i}$, and one where this inequality is reversed. We could repeat the argument this time using the variance of $P(A)$ on the latter.

Lemma 2 If $(\sigma, P)$ is IC, then $U_{i}\left(A_{i} ; \sigma, P\right)$ is continuous and monotone decreasing in $A_{i}$. Monotonicity is strict if $1>P_{i}\left(A_{i}\right)+A_{i}$.

Proof. Continuity is trivial. Now let $A_{i}>A_{i}^{\prime}$. From IC,

$$
\begin{aligned}
& U_{i}\left(A_{i} ; \sigma, P\right)-U_{i}\left(A_{i}^{\prime} ; \sigma, P\right) \leq \\
& \Psi_{i}\left(A_{i}\right)\left[\int_{0}^{\min \left\{1, P_{i}\left(A_{i}\right)+A_{i}\right\}}\left(P_{i}\left(A_{i}\right)+A_{i}-c\right) d c-A_{i}\right]- \\
& \Psi_{i}\left(A_{i}\right)\left[\int_{0}^{\min \left\{1, P_{i}\left(A_{i}\right)+A_{i}^{\prime}\right\}}\left(P_{i}\left(A_{i}\right)+A_{i}^{\prime}-c\right) d c-A_{i}^{\prime}\right] \\
= & \Psi_{i}\left(A_{i}\right)\left[\int_{\min \left\{1, P_{i}\left(A_{i}\right)+A_{i}^{\prime}\right\}}^{\min \left\{1, P_{i}\left(A_{i}\right)+A_{i}\right\}}\left(P_{i}\left(A_{i}\right)-c\right) d c\right. \\
& \left.-A_{i}\left[1-\min \left\{1, P_{i}\left(A_{i}\right)+A_{i}\right\}\right]+A_{i}^{\prime}\left[1-\min \left\{1, P_{i}\left(A_{i}\right)+A_{i}^{\prime}\right\}\right]\right] \\
\leq & -A_{i}^{\prime}\left[\min \left\{1, P_{i}\left(A_{i}\right)+A_{i}\right\}-\min \left\{1, P_{i}\left(A_{i}\right)+A_{i}^{\prime}\right\}\right] \\
& -A_{i}\left[1-\min \left\{1, P_{i}\left(A_{i}\right)+A_{i}\right\}\right]+A_{i}^{\prime}\left[1-\min \left\{1, P_{i}\left(A_{i}\right)+A_{i}^{\prime}\right\}\right] \\
= & -\left(A_{i}-A_{i}^{\prime}\right)\left[1-\min \left\{1, P_{i}\left(A_{i}\right)+A_{i}\right\}\right] \leq 0 .
\end{aligned}
$$

The penultimate inequality follows from the fact that $P_{i}(A)-c$ is decreasing in $c$, and an integral increases if we substitute the maximum of the integrand for the integrand itself.

Lemma 3 In any IC mechanism $\Psi_{i}\left(A_{i}\right)$ is monotonically decreasing and $P\left(A_{i}\right)$ monotonically increasing. 
Proof. Let $A_{i}^{\prime}>A_{i}$. Define for arbitrary values $P, x$

$$
\Pi_{i}(P, x)=\int_{0}^{\min \{1, P+x\}}(P+x-c) d c-x
$$

Then by incentive compatibility

$$
\begin{aligned}
& \Psi\left(A_{i}\right) \Pi_{i}\left(P\left(A_{i}\right), A_{i}\right) \geq \Psi\left(A_{i}^{\prime}\right) \Pi_{i}\left(P\left(A_{i}^{\prime}\right), A_{i}\right) \\
& \Psi\left(A_{i}^{\prime}\right) \Pi_{i}\left(P\left(A_{i}^{\prime}\right), A_{i}^{\prime}\right) \geq \Psi\left(A_{i}\right) \Pi_{i}\left(P\left(A_{i}\right), A_{i}^{\prime}\right)
\end{aligned}
$$

Combining these two equations we get

$\Psi\left(A_{i}\right)\left[\Pi_{i}\left(P\left(A_{i}\right), A_{i}\right)-\Pi_{i}\left(P\left(A_{i}\right), A_{i}^{\prime}\right)\right] \geq \Psi\left(A_{i}^{\prime}\right)\left[\Pi_{i}\left(P\left(A_{i}^{\prime}\right), A_{i}\right)-\Pi_{i}\left(P\left(A_{i}^{\prime}\right), A_{i}^{\prime}\right)\right]$

Note that $\Pi_{i}\left(P, A_{i}\right)$ is decreasing in $A_{i}$ and increasing (non-decreasing) in $P$.

Also, $\Pi_{i}\left(P, A_{i}\right)-\Pi_{i}\left(P, A_{i}^{\prime}\right)$ is decreasing in $P$. Indeed,

$$
\begin{gathered}
\Pi_{i}\left(P, A_{i}\right)-\Pi_{i}\left(P, A_{i}^{\prime}\right)= \\
= \begin{cases}\int_{P+A_{i}}^{P+A_{i}^{\prime}}\left(c-P-A_{i}\right) d c+\int_{P+A_{i}^{\prime}}^{1}\left(A_{i}^{\prime}-A_{i}\right) d c & \text { if } P<1-A_{i}^{\prime}, \\
\int_{P+A_{i}}^{1}\left(c-P-A_{i}\right) d c & \text { if } 1-A_{i}^{\prime} \leq P<1-A_{i}, \\
0 & \text { if } P \geq 1-A_{i}\end{cases}
\end{gathered}
$$

Thus, if $P<1-A_{i}$,

$$
\frac{d\left[\Pi_{i}\left(P, A_{i}\right)-\Pi_{i}\left(P, A_{i}^{\prime}\right)\right]}{d P}=-\left[\max \left(1, P+A_{i}^{\prime}\right)-\left(P+A_{i}\right)\right]<0
$$

Now, assume for contradiction that $P\left(A_{i}^{\prime}\right)<P\left(A_{i}\right)$ which since $\prod_{i}\left(P, A_{i}\right)-$ $\Pi_{i}\left(P, A_{i}^{\prime}\right)$ is decreasing in $P$ implies that

$$
\left[\Pi_{i}\left(P\left(A_{i}\right), A_{i}\right)-\Pi_{i}\left(P\left(A_{i}\right), A_{i}^{\prime}\right)\right] \leq\left[\Pi_{i}\left(P\left(A_{i}^{\prime}\right), A_{i}\right)-\Pi_{i}\left(P\left(A_{i}^{\prime}\right), A_{i}^{\prime}\right)\right]
$$

Given (13) the inequality(12) can only be satisfied if $\Psi\left(A_{i}^{\prime}\right) \leq \Psi\left(A_{i}\right)$. But $P\left(A_{i}^{\prime}\right)<P\left(A_{i}\right)$ and $\Psi\left(A_{i}^{\prime}\right) \leq \Psi\left(A_{i}\right)$ violates the incentive compatibility constraint of type $A_{i}^{\prime}$ (equation 11). Hence $P\left(A_{i}^{\prime}\right)>P\left(A_{i}\right)$. But then $\Psi\left(A_{i}^{\prime}\right) \leq$ 
$\Psi\left(A_{i}\right)$. Otherwise the incentive compatibility constraint of type $A_{i}$ would be violated (equation 10).

Lemma 4 Two mechanisms that share $\Psi_{i}\left(A_{i}\right)$ and give the same rents to bidders of the highest type also share $P_{i}\left(A_{i}\right)$.

Proof. Given that $P_{i}\left(A_{i}\right)$ is monotone increasing, assume that $P_{i}(\bar{A})+\bar{A} \leq$ 1. Otherwise, what follows would hold true just by substituting $\sup \left\{A_{i}\right.$ : $\left.P_{i}\left(A_{i}\right) \leq 1\right\}$ for $\bar{A}$. Let us fix $U_{i}(\bar{A} ; \sigma, P)$. We can compute $U_{i}\left(A_{i} ; \sigma, P\right)$ as:

$$
U_{i}\left(A_{i} ; \sigma, P\right)=\Psi_{i}\left(A_{i}\right)\left[\int_{0}^{P_{i}\left(A_{i}\right)+A_{i}}\left(P_{i}\left(A_{i}\right)-c+A_{i}\right) d c-A_{i}\right] .
$$

Therefore, the derivative of the utility whenever this derivative and $P_{i}^{\prime}$ exist, is

$$
\begin{aligned}
& \Psi_{i}^{\prime}\left(A_{i}\right)\left[\int_{0}^{P_{i}\left(A_{i}\right)+A_{i}}\left(P_{i}\left(A_{i}\right)-c+A_{i}\right) d c-A_{i}\right]+\Psi_{i}\left(A_{i}\right)\left[\left(P_{i}\left(A_{i}\right)+A_{i}\right)\left(P_{i}^{\prime}\left(A_{i}\right)+1\right)-1\right]= \\
& \Psi_{i}^{\prime}\left(A_{i}\right)\left[\int_{0}^{P_{i}\left(A_{i}\right)+A_{i}}\left(P_{i}\left(A_{i}\right)-c+A_{i}\right) d c-A_{i}\right]+\Psi_{i}\left(A_{i}\right)\left(P_{i}\left(A_{i}\right)+A_{i}\right) P_{i}^{\prime}\left(A_{i}\right) \\
& -\left(1-\left(P_{i}\left(A_{i}\right)+A_{i}\right)\right) \Psi_{i}\left(A_{i}\right) .
\end{aligned}
$$

But from IC we know that $U_{i}^{\prime}\left(A_{i} ; \sigma, P\right)=-\left[1-\left(P_{i}\left(A_{i}\right)+A_{i}\right)\right] \Psi_{i}\left(A_{i}\right)$. Therefore we conclude that in an IC mechanism

$$
\frac{\Psi_{i}^{\prime}\left(A_{i}\right)}{\Psi_{i}\left(A_{i}\right)}=-\frac{P_{i}\left(A_{i}\right)+A_{i}}{\int_{0}^{P_{i}\left(A_{i}\right)+A_{i}}\left(P_{i}\left(A_{i}\right)-c+A_{i}\right) d c-A_{i}} P_{i}^{\prime}\left(A_{i}\right) .
$$

Thus, given $P, \Psi_{i}^{\prime}$ is determined at all points where $\Psi_{i}^{\prime}$ and $P_{i}^{\prime}$ exist. Since both $P$ and $\Psi$ are monotone and bounded, these derivatives exist almost everywhere. Continuity of $U_{i}$ also implies that jumps in $P$ determine the size of jumps in $\Psi$ uniquely. Then the lemma follows. 
Lemma 5 For any $C_{B} \geq 0$, there exist non strictly monotone, IC mechanisms that result in higher surplus for the buyer than mechanisms that assign the contract to the bidder with lowest $A$ (auctions) if $f^{\prime}(A)$ exists and is negative for $A$ close to $\bar{A}$.

Proof. Given $\Psi(A)=[1-F(A)]^{n-1}$, and $P(\bar{A})$, where we dispense with subscripts by virtue of symmetry, construct a new mechanism $\Psi^{*}(A), P^{*}(A)$ where $\Psi^{*}(A)=\Psi(A)$ for all $A \leq A^{*}$, and for all $A>A^{*}, \Psi^{*}(A)=$ $\frac{\left[1-F\left(A^{*}\right)\right]^{n-1}}{n}$, for some value $A^{*}$. Note that $\Psi^{*}$ is obtained by assigning the contract to the firm with lowest type if that type is below $A^{*}$, and otherwise randomizing the allocation. That is, $\sigma^{*}$ exists. Also, for $A>A^{*}$, let $P^{*}(A)=P(\bar{A})$, and $P^{*}\left(A^{*}\right)$ be such that $U(A)$ is continuous at $A^{*}$. This completely determines the mechanism. Moreover, the mechanism is incentive compatible and individually rational. We now show that for $A^{*}$ sufficiently close to $\bar{A}$ the firms' rents are lower in the new mechanism than in the original. In fact, it suffices to show that, for $A^{*}$ sufficiently close to $\bar{A}$, the rents of a bidder with type $A^{*}$ in the auction, $U\left(A^{*}\right)$, are larger than in the new mechanism, $U^{*}\left(A^{*}\right)$. Indeed, the slope of the rents in both mechanisms is the same for types below $A^{*}$, and the difference in rents $U^{*}(A)-U(A)$ for types above $A^{*}$ is bounded above by $U^{*}\left(A^{*}\right)$. For $A^{*}$ sufficiently close to $\bar{A}$, both $U^{*}\left(A^{*}\right)$ and $\left(1-F\left(A^{*}\right)\right)$ approach zero, and therefore its product is of second order. So, let us consider

$$
\begin{aligned}
& U^{*}\left(A^{*}\right)-U\left(A^{*}\right)= \\
& \int_{A^{*}}^{\bar{A}}[1-(P(\bar{A})+A)] \frac{\left[1-F\left(A^{*}\right)\right]^{n-1}}{n} d A-\int_{A^{*}}^{\bar{A}}[1-(P(A)+A)][1-F(A)]^{n-1} d A .
\end{aligned}
$$


The derivative of this expression with respect to $A^{*}$ is

$$
\begin{aligned}
& -\left[1-\left(P(\bar{A})+A^{*}\right)\right] \frac{\left[1-F\left(A^{*}\right)\right]^{n-1}}{n}+\left[1-\left(P\left(A^{*}\right)+A^{*}\right)\right]\left[1-F\left(A^{*}\right)\right]^{n-1} \\
& -\int_{A^{*}}^{\bar{A}}[1-(P(\bar{A})+A)] d A \frac{n-1}{n} f\left(A^{*}\right)\left[1-F\left(A^{*}\right)\right]^{n-2} .
\end{aligned}
$$

This is $\frac{1}{n} f\left(A^{*}\right)\left[1-F\left(A^{*}\right)\right]^{n-2}$ times

$$
\begin{aligned}
& \left(-\left[1-\left(P(\bar{A})+A^{*}\right)\right]+n\left[1-\left(P\left(A^{*}\right)+A^{*}\right)\right]\right) \frac{1-F\left(A^{*}\right)}{f\left(A^{*}\right)} \\
& +(n-1) \int_{A^{*}}^{\bar{A}}[1-(P(\bar{A})+A)] d A .
\end{aligned}
$$

The derivative of (15) with respect to $A^{*}$ is

$$
\begin{aligned}
& \left(1-n\left[P^{\prime}\left(A^{*}\right)+1\right]\right) \frac{1-F\left(A^{*}\right)}{f\left(A^{*}\right)}+(n-1)\left[1-\left(P(\bar{A})+A^{*}\right)\right]+ \\
& \frac{d}{d A^{*}}\left[\frac{1-F\left(A^{*}\right)}{f\left(A^{*}\right)}\right]\left(-\left[1-\left(P(\bar{A})+A^{*}\right)\right]+n\left[1-\left(P\left(A^{*}\right)+A^{*}\right)\right]\right) .
\end{aligned}
$$

The first term is negative, since $P^{*}>0$. Also, if $f^{\prime}<0$ then $\frac{d}{d A^{*}}\left[\frac{1-F\left(A^{*}\right)}{f\left(A^{*}\right)}\right]<$ -1 , and so the second and third terms together are smaller than

$$
n\left(\left[1-\left(P(\bar{A})+A^{*}\right)\right]-\left[1-\left(P\left(A^{*}\right)+A^{*}\right)\right]\right)<0 .
$$

Thus, (15) is decreasing in $A^{*}$ and attains a value of 0 at $A^{*}=\bar{A}$. Therefore, for $A^{*}$ close to $\bar{A}$ it takes a positive value. This proves that $U^{*}\left(A^{*}\right)-U\left(A^{*}\right)$ is increasing in $A^{*}$ for values of $A^{*}$ close to $\bar{A}$. Since $U^{*}\left(A^{*}\right)-U\left(A^{*}\right)=0$ for $A^{*}=\bar{A}$, we conclude that $U^{*}\left(A^{*}\right)<U\left(A^{*}\right)$ for values of $A^{*}$ close to $\bar{A}$. This proves the result.

\section{References}

Arditi, D., Koksal, A. and Kale, S. (2000) "Business Failure in the Construction Industry", Engineering, Construction and Architectural Manage- 
ment 7, 120-132

Board, S. (2007) "Bidding into the Red. A model of Post-Auction Bankruptcy", Journal of Finance LXII (6) 2695-2723

Calveras, A., Ganuza, J. and Hauk, E. (2004). "Wild Bids. Gambling for Resurrection in Procurement Contracts", Journal of Regulatory Economics 26(1): 41-68.

Che, Y. and Gale, I. (1996). "Financial Constraints in Auctions: Effects and Antidotes.", Advances in Applied Microeconomics 6: 97-120

Che, Y. and Gale, I. (2000) "The Optimal Mechanism for Selling to a Budget-Constrained Buyer", Journal of Economic Theory 92: 198-233

Decarolis, F. (2008) "When the Highest Bidder Loses the Auction: Theory and Evidence from Public Procurement", mimeo, University of Chicago

Engel, A.R. and Wambach. A. (2006) "Public Procurement under limited liability", Revista di politica economica 96(1/2): 13-40

Manelli, A.M. and Vincent, D.R. (1995) "Optimal Procurement Mechanism", Econometrica 63(3): 591-620

Pai, M.M. and Vohra, R. (2008) "Optimal Auctions with Financially Constrained Bidders", mimeo, Kellog School of Management, Northwestern University

Waehrer, K. (1995). "A Model of Auction Contracts with Liquidated Damages", Journal of Economic Theory 67: 531-555 
White, M.J. (1989) "The Corporate Bankruptcy Decision", Journal of Economic Perspectives 3: 129-151

Zheng, C. Z. (2001). "High Bids and Broke Winners", Journal of Economic Theory 100: 129-171. 